Check for updates

The BMJ

kabbasi@bmi.com Follow Kamran on

Twitter@KamranAbbasi

Cite this as: $B M / 2022 ; 376: 0274$

http://dx.doi.org/10.1136/bmj.0274

Published: 03 February 2022

\title{
Medical research needs a Sue Gray
}

\section{Kamran Abbasi editor in chief}

Research in medicine needs someone with the power to investigate and uncover misconduct by professionals and organisations who abuse people's trust. Trial participants have every faith in the research enterprise that they sign up for, but it is often misplaced. Trials remain unregistered, and too many are registered retrospectively. Results are released too slowly or suppressed. And trial data are reluctantly or never shared (doi:10.1136/bmj.0102). ${ }^{1}$ Data may even be fabricated (doi:10.1136/bmj.0216). ${ }^{2}$ Automatic registration of clinical trials in the UK after approval by ethics committees is therefore a welcome advance (doi:10.1136/bmj.041).

Too much bad practice is tolerated in the name of commercial considerations. The drug industry, for example, achieves the highest profit margins and does particularly well during recessions, but it won't waive covid intellectual property rights to support global vaccine availability and save lives, for fear of harming future income (doi:10.1136/bmj-2021067367).

"The biggest treatment disaster in the NHS" is one way to describe trials that used contaminated blood products to treat children with haemophilia in the 1970 and 1980 s without informed consent from them or their parents. Some of the survivors are now seeking compensation (doi:10.1136/bmj.0217). ${ }^{5}$ What does it say about us as a society when we turn trials-a public good-into a tool of exploitation and fail to learn from history?

Yet, well conducted clinical trials support important advances in thinking. A new trial we publish this week reports benefits of intravenous ketamine for the acute treatment of suicidal ideation (doi:10.1136/bmj-2021-067194). ${ }^{6}$ Our latest update on treatments for covid-19 delivers a strong recommendation for baricitinib, a janus kinase inhibitor, in severe and critical covid (doi:10.1136/bmj.m3379 ). ${ }^{7}$ It also reminds us of the time, energy, and money wasted on advocacy and promotion of remdesivir, ivermectin, hydroxychloroquine, and convalescent plasma as covid treatments.

Research into long covid is also ripe for a clinical trial approach, but the response across Europe is fragmented and, other than in the UK, lacks adequate research funding (doi:10.1136/bmj.0158). ${ }^{8}$ Where clinical trials aren't able to tread, routinely collected data are meeting needs for rapid information. New data show that hospital admission for covid increases the risks of readmission and death (doi:10.1136/bmj.0265). ${ }^{9}$ The data on overall deaths continues to run above predicted levels (doi:10.1136/bmj.0254), ${ }^{10}$ and the higher risk of death from covid among ethnic minorities might be explained by lower vaccination rates (doi:10.1136/bmj.0233). ${ }^{11}$
A nationwide registry study from Norway finds a substantial short term increase in children's use of primary care in the first month after a positive SARS-CoV-2 test result without, importantly, an effect on hospital services (doi:10.1136/bmj-2021-066809; doi:10.1136/bmj.0143). ${ }^{1213}$ Workload pressures in primary care raise the question: how many GPs is enough? John Appleby explains why it is a hard question to answer (doi:10.1136/bmj.0123). ${ }^{14}$ And total staff numbers do not reflect illness, absence, or demand. The workforce solution isn't, despite being mooted by England's health secretary, for GPs to be employed directly by hospitals (doi:10.1136/bmj.0267; doi:10.1136/bmj.026o; doi:10.1136/bmj.0259; doi:10.1136/bmj.0251). ${ }^{15-18}$

None of this helps the "feeling of being lost in the increasingly vast gap between the care that they [professionals] want to deliver to their patients and what they can provide" (doi:10.1136/bmj.0197; doi:10.1136/bmj.0240). ${ }^{1920}$ It doesn't allow us to dwell on the intricacies of diagnostic reasoning, although we probably should (doi:10.1136/bmj-2021-064389). ${ }^{21}$ It doesn't reconcile the reality of being isolated from dying relatives with leaders partying on at the seat of power (doi:10.1136/bmj.0273).22 Sue Gray's inquiry and medical research share at least one theme: the widening gap between what people in power say they want to deliver and what they in reality provide.

Doshi P, Godlee F, Abbasi K. Covid-19 vaccines and treatments: we must have raw data, now. BMJ2022;376:0102

doi: 10.1136/bmj.0102 pmid: 35045956

Identifying false data . . . and other stories. BMJ2022;376:0216.

Bradley SH, Lloyd KE, DeVito NJ. Automatic registration for UK trials. BMJ 2022;376:041. doi: 10.1136/bmi.041 pmid: 35031535

4 Hawksbee L, McKee M, King L. Don't worry about the drug industry's profits when considering a waiver on covid-19 intellectual property rights. BMJ 2022;376:e067367. doi: 10.1136/bmj-2021-067367 pmid: 35101900

5 Dyer C. Former pupils of school for haemophiliac children seek legal redress for treatment with contaminated plasma. BMJ2022;376:0217. doi: 10.1136/bmj.0217 pmid: 35082138

6 Mocrane A, Demattei C, El-Hage W, etal. Ketamine for the acute treatment of severe suicidal ideation: double blind, randomised placebo controlled trial. BMJ2022;376:e067194

7 Agarwal A, Rochwerg B, Lamontagne F, etal. A living WHO guideline on drugs for covid-19. BM/2020;370:m3379. doi: 10.1136/bmj.m3379 pmid: 32887691

8 Baraniuk C. Covid-19: How Europe is approaching long covid. BMJ 2022;376:0158. doi: 10.1136/bmj.0158 pmid: 35058230

9 Torjesen I. Covid-19 patients discharged from hospital have "substantially higher risk" of adverse outcomes and need monitoring. BMJ 2022;376:0265doi: 10.1136/bmj.o265

10 lacobucci G. Covid-19: unravelling the conundrum of omicron and deaths. BMJ 2022;376:0254. doi: 10.1136/bmj.0254 pmid: 35091392

11 Torjesen I. Covid-19: Lower vaccination rates partly explain higher death rates among minority ethnic groups. BMJ 2022;376:0233. doi: 10.1136/bmj.0233 pmid: 35086890

12 Magnusson K, Skyrud KD, Suren P, etal. Healthcare use in 700000 children and adolescents for six months after covid-19: before and after register based cohort study. BM/2022;376:e66809. doi: 10.1136/bmj-2021-066809 pmid: 35039315

13 Zimmermann P, Pittet LF, Curtis N. Long covid in children and adolescents. BMJ 2022;376:0143. doi: 10.1136/bmj.0143 pmid: 35058281 
14 Appleby J. Planning the healthcare workforce: how many GPs do we need?BMJ 2022;376:0123doi: 10.1136/bmj.0123.

15 lacobucci G. Government wants more GPs to be employed by hospital trusts, says news report. BMJ 2022;376:0267doi: 10.1136/bmj.0267 .

16 Salisbury H. Helen Salisbury: Sajid Javid's plan for a salaried GP service. BMJ 2022;376:0260doi: 10.1136/bmj.o260.

17 Oliver D. David Oliver: Making GPs hospital employees won't solve pressure on hospitals or general practice. BMJ 2022;376:0259doi: 10.1136/bmj.o259 .

18 Vize R. Instead of gimmicks, the NHS needs a workforce plan. BMJ2022;376:0251.

19 Choo E. Working in healthcare right now means being asked to do the impossible-then being abandoned to our inevitable failure. BM/2022;376:0197. doi: 10.1136/bmj.0197 pmid: 35074929

20 Mathew R. Rammya Mathew: The difference between a doctor and a family doctor. BMJ 2022;376:0240doi: 10.1136/bmj.o240.

21 Brush JE, JrSherbino J, Norman GR. Diagnostic reasoning in cardiovascular medicine. BMJ 2022;376:e064389. doi: 10.1136/bmj-2021-064389 pmid: 34987062

22 Greenhalgh T. Gray report: "Failures of leadership and judgement. BMJ 2022;376:0273doi: 10.1136/bmj.o273 . 